\title{
Dopamine (3-Hydroxytyramine) Replacement and
}

\author{
Metabolism in Sympathetic Nerve and Adrenal
}

\section{Medullary Depletions After Prolonged Thermal Injury}

\author{
McC. Goodall and Harold Alton \\ From the Department of Surgery and Physiology, University of Texas Medical \\ Branch, Galveston, Texas 77550
}

A B S T R A C T After severe thermal injury, the adrenal medulla and the sympathetic nerves can be partially or totally depleted of their adrenaline (epinephrine) and noradrenaline (norepinephrine). The purpose of this paper is to elucidate the rate at which dopamine- $2-{ }^{14} \mathrm{C}$, a precursor of noradrenaline, is synthesized into noradrenaline and noradrenaline metabolic products, thereby giving some indication as to dopamine's utilization, turnover, and possible use in treating such noradrenalineadrenaline depletions. Three burned subjects, 3 wk postburn, were infused with $104.6 \mu \mathrm{c}(872 \mu \mathrm{g})$ of dopamine-

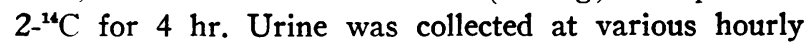
intervals for the 1st day, and thereafter for 4 days, assayed, and compared with the metabolism of dopamine in normal subjects. Methods for separating, identifying, and counting radioactivity of the various metabolic products of dopamine are described. Normally 87.6 $\pm 3.1 \%$ of the total radioactivity is recovered within $24 \mathrm{hr}$ after an infusion of dopamine-2- ${ }^{16} \mathrm{C}$, but in the three severely burned patients, this value was increased to $93.1,97.3$, and $97.5 \%$ in $24 \mathrm{hr}$. There was a marked decrease in the percentage of radioactivity recovered as noradrenaline in all collection periods, and in contrast to normal subjects, no radioactive noradrenaline was recovered after $24 \mathrm{hr}$. Concomitantly, there was an increase in radioactivity recovered as metabolic products of noradrenaline, reflecting a compensatory shift toward noradrenaline synthesis and utilization at the expense of the dopamine metabolic products. The results indicate that in the burned patients the infused dopamine-2${ }^{16} \mathrm{C}$ was rapidly synthesized into noradrenaline and then rapidly released and metabolized. From these results it seems evident that dopamine would be a useful adjunct in the treatment of sympathico-adrenal medullary depletion in burns.

Received for publication 3 April 1969.

\section{INTRODUCTION}

There are many stressful conditions which stimulate the sympathicoadrenal medullary system into releasing increased amounts of noradrenaline (norepinephrine) from the sympathetic nerves and adrenaline (epinephrine) from the adrenal medulla (1-5). Of these stresses, thermal injury is probably one of the most potent (6-9). Goodall, Haynes, and Moncrief showed that the prolonged stress which accompanied severe thermal injury was of such magnitude that the adrenal glands could be partially or totally depleted of adrenaline (10) and the sympathetic nerves partially or totally depleted of noradrenaline (11). The purpose of this paper is io evaluate the rate of noradrenaline-adrenaline biosynthesis and utilization in severe prolonged thermal injury and thereby obtain information as to how this depletion might be treated.

\section{METHODS}

\section{General}

Three severely burned patients were infused with dopamine-2- ${ }^{14} \mathrm{C}$ (3-hydroxytyramine, 3,4-dihydroxyphenylethylamine), the immediate precursor in the biosynthesis of noradrenaline (see Fig. 1). Infusion was purposely delayed until $3 \mathrm{wk}$ after the burn, since it is at this time that the depletion of adrenaline and noradrenaline most commonly manifests itself $(6,10,11)$. Whereas, the patients were being treated, nevertheless, at the time of the dopamine infusion, they were not receiving any therapy that in itself would alter dopamine metabolism. Summary of patients is as follows :

L. H., $37 \mathrm{yr}$ old male, $63 \%$ burned with mixed second and third degree, Curling's ulcer present, lived.

P. M., 43 yr old male, $50 \%$ burned, $45-50 \%$ third degree, died.

R. M., 59 yr old male, $36 \%$ burned, with $33 \%$ third degree, died. 


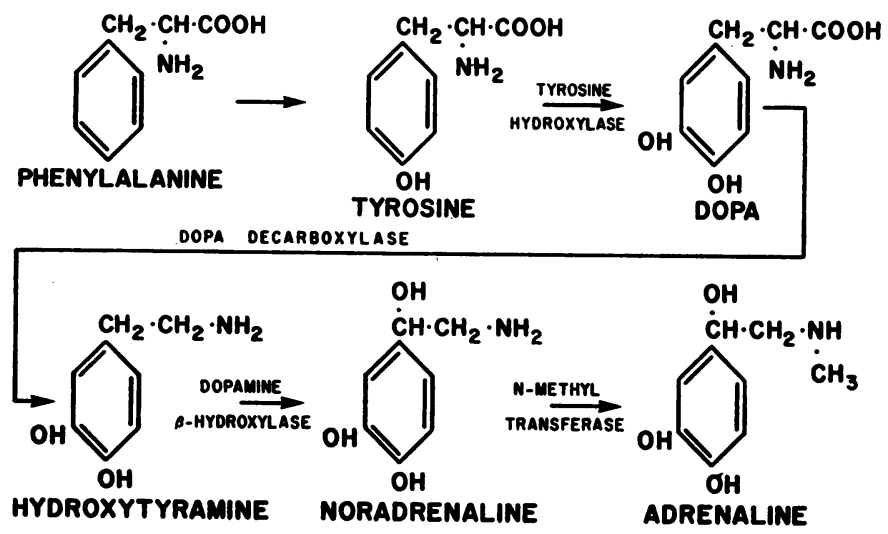

FIGURE 1 Biosynthetic pathway to the formation of noradrenaline (norepinephrine) and adrenaline (epinephrine).

Each patient was infused with $104.6 \mu \mathrm{c}(872 \mu \mathrm{g})$ of dopamine-2- ${ }^{14} \mathrm{C}$ (SA, $32 \mathrm{mc} / \mathrm{mmole}$ ). The labeled dopamine was dissolved in $1000 \mathrm{ml}$ of physiological saline and infused via the antecubital vein at a constant rate over a period of $4 \mathrm{hr}$. Urine was collected during the infusion period and at 2, 4, 8, and $24 \mathrm{hr}$, and at the end of the 2nd, 3rd, 4th, and 5th days. The method for isolating and quantifying endogenous noradrenaline and the metabolic products of noradrenaline, as well as the metabolic products of dopamine, has been previously described $(12,13)$. In brief, it is as follows:

Separation of acidic compounds. An aliquot of urine containing $100,000 \mathrm{dpm}$ to which was added carrier compounds of 3-methoxy-4-hydroxymandelic acid (MOMA), 3-methoxy4-hydroxyphenylacetic acid (HVA), 3,4-dihydroxymandelic acid (DOMA), and 3,4-dihydroxyphenylacetic acid (DOPAC) was placed on $1 \times 35 \mathrm{~cm}$ column of Dowex-1-X2 acetate anion-exchange resin. The column was placed on an automatic fraction collection system and eluted with a gradient elution system consisting of ammonium acetate buffers of varying molarity and acidity.

The eluate was passed through a quartz flow cell of a Beckman DB-G Spectrophotometer and the optical density measured at $279 \mathrm{~m} \mu$. The optical density was recorded on one channel of a dual-channel recorder. After the eluate passed through the DB-G Spectrophotometer, it entered a $10 \mathrm{ml}$ flow cell, and the radioactivity was counted with a specially developed flow system, i.e., Packard Experimental, analog, digital flow system. The output was recorded on the other channel of the dual recorder. From the fraction collector, an impulse was relayed to an event marker on the recorder so as to indicate the change of each fraction by the fraction collector. For a typical tracing, see Fig. 2.

Those fractions comprising a single radioactivity peak were pooled and assayed for total radioactivity. The recovery of the total radioactivity placed on the Dowex-1 column was $97 \pm 6 \%$. The peaks containing specific free phenolic acids, such as MOMA, HVA, DOMA, and DOPAC were confirmed by paper chromatography in three different solvent systems, i.e., $n$-butanol- $N$-acetic acid- $\mathrm{H}_{2} \mathrm{O}$ (4:1:1), benzene-proprionic acid- $\mathrm{H}_{2} \mathrm{O}(4: 1: 1)$, and isopropanol-5\% $\mathrm{NH}_{3}(8: 2)$. The conjugates of HVA, MOMA, and DOPAC were identified by refluxing the ammonium acetate-free peak in $3 \mathrm{~N} \mathrm{H}_{2} \mathrm{SO}_{4}$ followed by extraction into ether and chromatography of the resulting compound with appropriate carrier compounds in different solvent systems. The conjugates of 3-methoxytyramine (3-MT), normetadrenaline $(\mathrm{NM})$, noradrenaline, and dopamine were identified by hydrolysis of the conjugated amine in $2 \mathrm{~N} \mathrm{H}_{2} \mathrm{SO}_{4}$ followed by ion-exchange absorption and chromatography of the free amines on IRC-50 Amberlite resin; the normetadrenaline conjugate peak also contained significant amounts of noradrenaline conjugate which was separated and measured.

Separation of the basic compounds. An aliquot of urine containing $500,000 \mathrm{dpm}$ was placed on a $60 \times 0.9 \mathrm{~cm}$ column of Amberlite IRP-64 resin along with carrier compounds of adrenaline (epinephrine), metadrenaline (3-O-methyladrenaline, metanephrine), NM (3-O-methylnoradrenaline, normetanephrine), noradrenaline, dopamine, and 3-MT. The column was washed with $20 \mathrm{ml}$ of $0.2 \mathrm{M}$ ammonium acetate buffer, $\mathrm{pH}$ 6.2, attached to the above described flow monitoring system, and eluted with $0.3 \mathrm{M}$ ammonium acetate buffer, $\mathrm{pH} 5.0$, followed by $0.4 \mathrm{~m}$ buffer. The identity of the radioactive peaks is determined and confirmed by paper chromatography. Adrenaline and NM elute from the column at the same point, but further separation procedures produced only small to trace amounts of adrenaline.

\section{RESULTS}

From the results it is evident that there is an increase in the rate of utilization of dopamine. Normally 87.6 $\pm 3.1 \%$ of the total radioactivity is recovered within 24 $\mathrm{hr}$ after an infusion of dopamine- $2-{ }^{14} \mathrm{C}$, but in the severely burned patients $93.1,97.3$, and $97.5 \%$ were recovered in $24 \mathrm{hr}$, (see Table I). Very little radioactivity is recovered after $24 \mathrm{hr}$.

In the burned subjects there is a marked decrease in the percentage of radioactivity recovered as noradrenaline in all collection periods, and contrary to normal subjects, no radioative noradrenaline recovered after $24 \mathrm{hr}$. Concomitantly, there is an increase in radioactivity recovered as specific metabolic products of noradrenaline, i.e., noradrenaline conjugate, NM conjugate, and MOMA in the early collection periods (see Table I). 


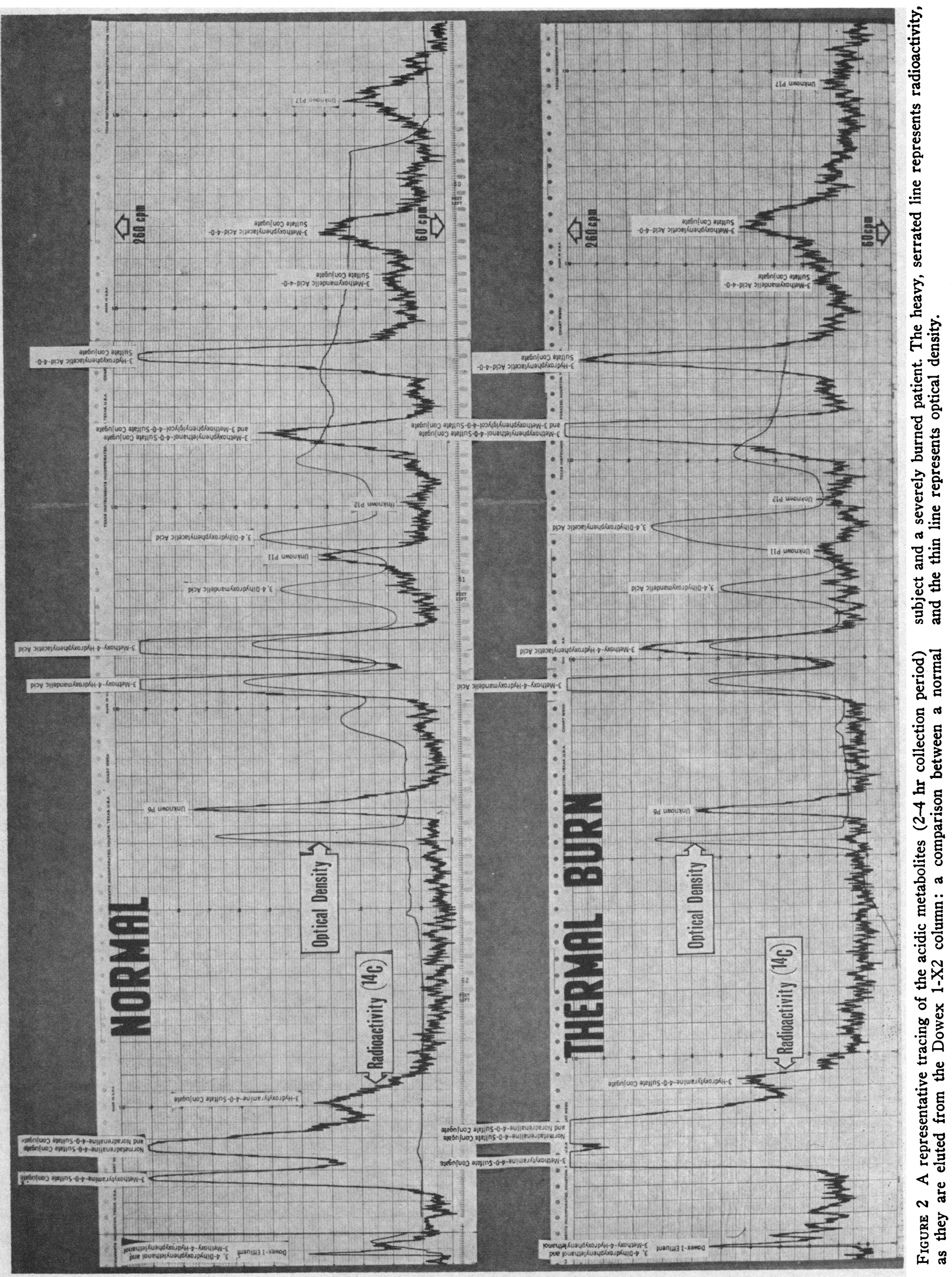


It has been previously shown (12) that in normal subjects after an infusion of dopamine approximately $25 \%$ of the dopamine is converted to noradrenaline and its metabolic products and about $75 \%$ to metabolic products of dopamine, i.e., principally HVA, DOPAC, and their respective $O$-sulfate conjugates. In the severely burned subjects approximately $30 \%$ was converted to noradrenaline and noradrenaline metabolic products, and $70 \%$ is recovered as dopamine and metabolic products of dopamine.

There was a small increase in the recovery of radioactivity as conjugates of dopamine, 3-MT, and 3-methoxy4-hydroxyphenylethanol (MHPE) but a decrease in HVA, the principal metabolite of dopamine. There was

TABLE I

Excretion Pattern of the Metabolites and Biosynthetic Products of Intravenous

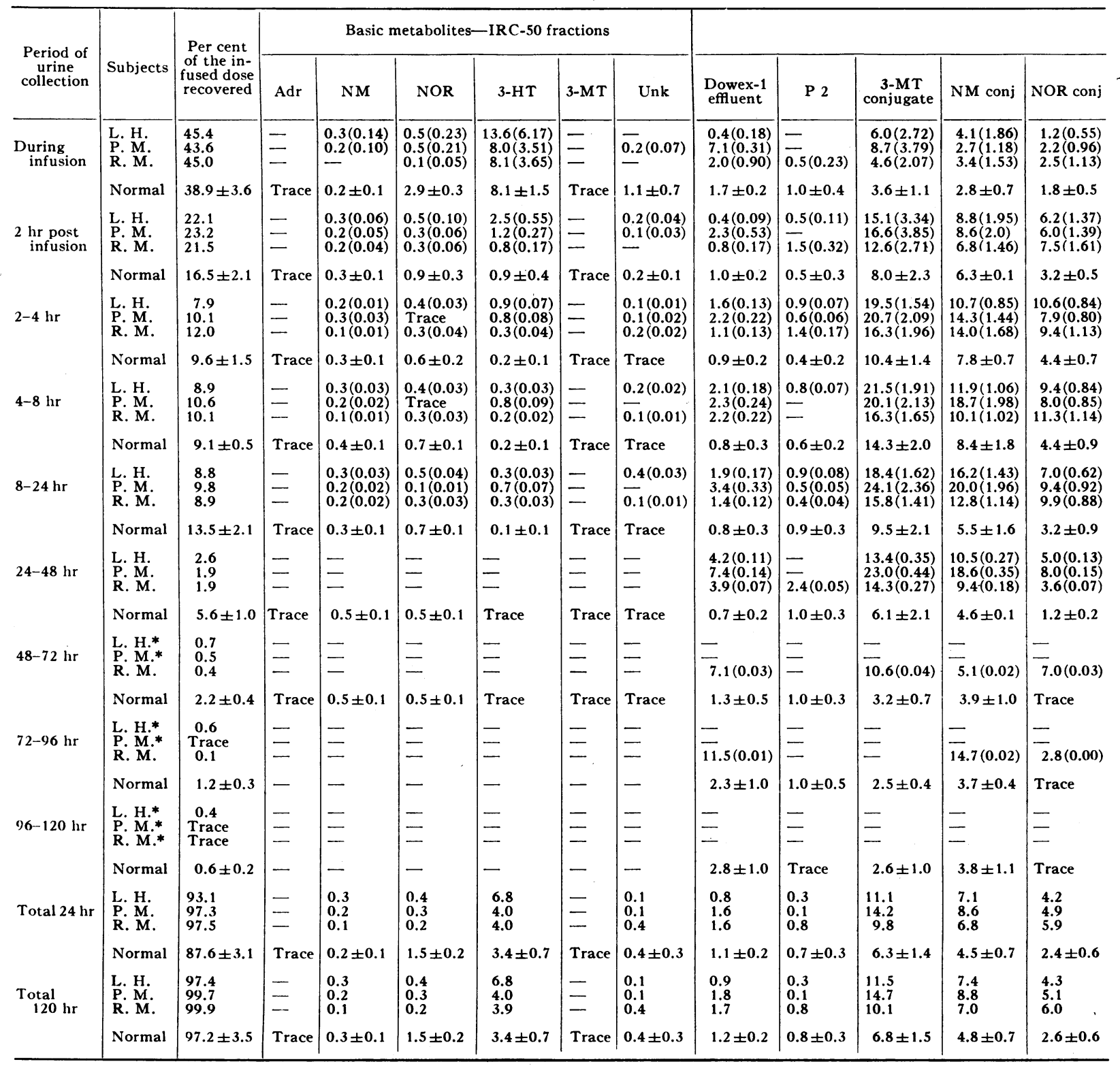

Excretion pattern of the basic metabolites, acidic metabolites, and biosynthetic products of dopamine after a $4 \mathrm{hr}$ infusion of dopamine-2-14 $\mathrm{C}$; comparison Adr, adrenaline; NM, normetadrenaline; NOR, noradrenaline; 3-H T, 3-hydroxytyramine (dopamine); 3-MT, 3-methoxytyramine; 3-M T conj, 3-methoxyconj, 3,4-dihydroxyphenylacetic acid conjugate: MOMA conj. 3-methoxy-4-hydroxymandelic acid conjugate; HVA conj, 3-methoxy-4-hydroxyphenyactivity recovered in each collection period; in parenthesis is the per cent of the infused dose recovered.

* Insufficient radioactivity for assay. 
no significant change in the conjugates of DOPAC and HVA; these metabolites are principally derived from dopamine.

Whereas there were significant decreases in the amount of radioactivity recovered as peak 6 and peak 11, the meaning behind this decrease is obscure since peak 6 and peak 11 have not yet been identified. However, it has been determined that they are metabolic products of dopamine rather than noradrenaline (12). In severely burned subjects the metabolism of dopamine is also altered in other ways; there are radioactive unknown compounds which appear in urine of burned subjects but which have not been observed in normal subjects (see Fig. 2).

Infused Dopamine (Hydroxytyramine-214 C) in Severe Thermal Injury

Acidic metabolites : Dowex-1 fractions

\begin{tabular}{|c|c|c|c|c|c|c|c|c|c|c|c|c|}
\hline HT conj & P 6 & MOMA & HVA & DOMA & Unk P 11 & DOPAC & Unk P 12 & $\underset{\text { conj }}{\text { MHPE \& }}$ & $\underset{\text { conj }}{\text { DOPAC }}$ & $\underset{\text { conj }}{\text { POMA }}$ & $\underset{\text { conj }}{\text { HVA }}$ & Unk P 17 \\
\hline $\begin{array}{l}1.2(0.55) \\
1.3(0.57) \\
3.2(1.44)\end{array}$ & $\begin{array}{l}1.1(0.50) \\
1.1(0.48) \\
1.8(0.81)\end{array}$ & $\begin{array}{l}5.9(2.68) \\
4.7(2.05) \\
4.4(1.98)\end{array}$ & $\begin{array}{l}33.8(15.35) \\
40.0(17.44) \\
29.1(13.10)\end{array}$ & $\begin{array}{l}\overline{1.2}(0.52) \\
1.0(0.45)\end{array}$ & $\underline{-}^{1.2(0.55)}$ & $\begin{array}{l}7.8(3.54) \\
8.2(3.58) \\
8.4(3.78)\end{array}$ & 二 & $\begin{array}{l}1.9(0.86) \\
2.0(0.87) \\
4.2(1.89)\end{array}$ & $\begin{array}{l}1.4(0.64) \\
2.6(1.13) \\
7.5(3.38)\end{array}$ & $\overline{\overline{2.1}}(0.95)$ & $\begin{array}{r}6.0(2.72) \\
6.8(2.97) \\
11.1(5.00)\end{array}$ & $\begin{array}{l}3.6(1.63) \\
2.4(1.05) \\
6.2(2.79)\end{array}$ \\
\hline $1.0 \pm 0.3$ & $1.9 \pm 0.7$ & $2.3 \pm 0.4$ & $47.8 \pm 2.9$ & Trace & $1.9 \pm 1.0$ & $2.0 \pm 1.2$ & $1.4 \pm 0.5$ & $3.0 \pm 1.2$ & $3.9 \pm 0.7$ & $1.4 \pm 0.4$ & $5.3 \pm 2.0$ & $4.3 \pm 1.0$ \\
\hline $\begin{array}{l}3.2(0.71) \\
2.7(0.63) \\
4.2(0.90)\end{array}$ & $\begin{array}{l}2.5(0.55) \\
2.3(0.53) \\
1.9(0.41)\end{array}$ & $\begin{array}{r}7.2(1.59) \\
10.3(2.39) \\
9.2(9.98)\end{array}$ & $\begin{array}{l}25.4(5.61) \\
24.5(5.68) \\
18.4(3.96)\end{array}$ & $\begin{array}{l}\overline{1.6}(0.37) \\
1.5(0.32)\end{array}$ & $\begin{array}{l}2.0(0.44) \\
1.3(0.30) \\
\text { Trace }\end{array}$ & $\begin{array}{l}3.0(0.66) \\
2.9(0.67) \\
2.6(0.56)\end{array}$ & 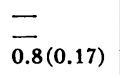 & $\begin{array}{r}10.1(2.23) \\
5.4(1.25) \\
9.8(2.11)\end{array}$ & & $\begin{array}{l}-\overline{0.3}(0.07) \\
2.1(0.45)\end{array}$ & $\begin{array}{l}5.3(1.17) \\
7.4(1.18) \\
6.1(1.31)\end{array}$ & $\begin{array}{l}3.0(0.66) \\
2.1(0.49) \\
3.6(0.77)\end{array}$ \\
\hline $2.5 \pm 0.5$ & $2.5 \pm 1.1$ & $6.5 \pm 1.0$ & $36.3 \pm 4.2$ & $1.5 \pm 0.5$ & $4.1 \pm 1.0$ & $4.0 \pm 0.6$ & $1.5 \pm 1.3$ & $2.8 \pm 1.0$ & $7.2 \pm 2.2$ & $2.4 \pm 1.0$ & $6.4 \pm 2.1$ & $6.0 \pm 1.5$ \\
\hline $\begin{array}{l}3.8(0.30) \\
3.6(0.36) \\
3.7(0.44)\end{array}$ & $\begin{array}{l}4.3(0.34) \\
4.2(0.42) \\
2.8(0.34)\end{array}$ & $\begin{array}{r}14.3(1.13) \\
8.5(0.86) \\
11.2(1.34)\end{array}$ & $\begin{array}{r}8.7(0.69) \\
10.4(1.05) \\
5.4(0.65)\end{array}$ & $\overline{\overline{\bar{Z}}}$ & $\frac{1.1(0.09)}{0.9}(0.11)$ & $\overline{1.3}(0.13)$ & $\begin{array}{l}1.2(0.10) \\
2.2(0.22) \\
1.1(0.13)\end{array}$ & $\begin{array}{r}7.5(0.59) \\
8.8(0.89) \\
13.0(1.56)\end{array}$ & & $\frac{1.3(0.10)}{2.0}(0.24)$ & $\begin{array}{l}3.7(0.29) \\
4.6(0.46) \\
5.6(0.67)\end{array}$ & $\frac{2.3(0.18)}{1.3(0.16)}$ \\
\hline $1.7 \pm 0.5$ & $4.3 \pm 1.3$ & $11.8 \pm 0.8$ & $20.4 \pm 1.6$ & $1.6 \pm 0.4$ & $1.5 \pm 0.4$ & $4.4 \pm 1.0$ & $1.3 \pm 0.4$ & $5.8 \pm 1.5$ & $8.6 \pm 1.9$ & $3.8 \pm 0.9$ & $6.0 \pm 0.9$ & $5.0 \pm 2.0$ \\
\hline $\begin{array}{l}3.5(0.31) \\
3.6(0.38) \\
2.9(0.29)\end{array}$ & $\begin{array}{l}5.3(0.47) \\
4.3(0.46) \\
2.9(0.29)\end{array}$ & $\begin{array}{r}18.8(1.67) \\
7.1(0.75) \\
11.7(1.18)\end{array}$ & $\begin{array}{l}2.0(0.18) \\
5.1(0.54) \\
3.5(0.35)\end{array}$ & 二 & $\begin{array}{l}1.2(0.11) \\
1.1(0.12)\end{array}$ & 二 & $\frac{1.7(0.15)}{1.7(0.17)}$ & $\begin{array}{r}8.8(0.78) \\
9.6(1.02) \\
15.7(1.59)\end{array}$ & $\begin{array}{r}7.6(0.68) \\
9.7(1.03) \\
10.6(1.07)\end{array}$ & $\begin{array}{l}2.1(0.19) \\
1.9(0.20) \\
2.4(0.24)\end{array}$ & $\begin{array}{l}2.1(0.19) \\
3.8(0.40) \\
5.4(0.55)\end{array}$ & $\begin{array}{l}\overline{3.1}(0.33) \\
2.6(0.26)\end{array}$ \\
\hline $2.8 \pm 0.3$ & $7.6 \pm 0.5$ & $15.8 \pm 1.5$ & $6.5 \pm 1.4$ & $1.2 \pm 0.2$ & $2.0 \pm 0.7$ & $1.7 \pm 0.5$ & $2.0 \pm 0.6$ & $7.1 \pm 0.9$ & $9.0 \pm 1.4$ & $3.7 \pm 1.0$ & $4.8 \pm 1.8$ & $6.6 \pm 2.0$ \\
\hline $\begin{array}{l}5.1(0.45) \\
5.8(0.57) \\
3.0(0.27)\end{array}$ & $\begin{array}{l}6.5(0.57) \\
4.8(0.47) \\
3.4(0.30)\end{array}$ & $\begin{array}{l}24.5(2.16) \\
11.9(1.17) \\
10.8(0.96)\end{array}$ & $\overline{-}$ & $\overline{-}$ & 二 & E & $\begin{array}{l}2.0(0.18) \\
1.2(0.12) \\
1.8(0.16)\end{array}$ & $\begin{array}{l}12.3(1.08) \\
11.0(1.08) \\
15.9(1.42)\end{array}$ & $\begin{array}{r}7.7(0.68) \\
4.8(0.47) \\
12.2(1.09)\end{array}$ & $\overline{\overline{3.1}}(0.28)$ & $\begin{array}{l}2.1(0.19) \\
1.8(0.18) \\
3.0(0.27)\end{array}$ & $\frac{2.2(0.19)}{2.6(0.23)}$ \\
\hline $2.3 \pm 0.8$ & $12.0 \pm 1.0$ & $23.4 \pm 3.7$ & $2.7 \pm 0.9$ & $0.9 \pm 0.4$ & $2.1 \pm 0.4$ & Trace & $2.5 \pm 0.7$ & $10.4 \pm 1.6$ & $11.1 \pm 3.0$ & $3.4 \pm 0.3$ & $4.7 \pm 0.3$ & $3.8 \pm 1.1$ \\
\hline $\begin{array}{l}3.5(0.09) \\
2.1(0.04) \\
6.8(0.15)\end{array}$ & $\begin{array}{r}10.6(0.28) \\
4.1(0.08) \\
3.3(0.06)\end{array}$ & $\begin{array}{r}29.8(0.78) \\
9.0(0.17) \\
7.9(0.15)\end{array}$ & $\bar{E}$ & $\overline{\overline{1.8}}(0.03)$ & 二 & 二 & $\frac{2.3(0.06)}{1.0(0.02)}$ & $\begin{array}{l}12.5(0.33) \\
10.1(0.19) \\
13.1(0.25)\end{array}$ & $\begin{array}{r}9.2(0.24) \\
6.4(0.12) \\
12.9(0.25)\end{array}$ & $\begin{array}{l}1.4(0.04) \\
\text { Trace } \\
2.4(0.05)\end{array}$ & $\begin{array}{l}2.2(0.06) \\
1.6(0.03) \\
6.3(0.12)\end{array}$ & $\begin{array}{l}\text { Trace } \\
\text { Trace } \\
\text { Trace }\end{array}$ \\
\hline Trace & $15.1 \pm 3.0$ & $35.9 \pm 3.8$ & $1.8 \pm 0.4$ & Trace & $2.3 \pm 0.2$ & Trace & $2.6 \pm 1.0$ & $11.6 \pm 2.1$ & $8.3 \pm 1.2$ & $2.8 \pm 1.0$ & $4.3 \pm 1.8$ & $2.2 \pm 0.6$ \\
\hline$\overline{\overline{4.9}}(0.02)$ & $\overline{\frac{-}{3.2(0.01)}}$ & $\overline{\overline{7}}$ & $\bar{E}_{2.3(0.01)}$ & $\overline{\overline{3.0}}(0.01)$ & 二 & 二 & 二 & $\overline{\overline{12}} .0(0.05)$ & $\overline{\overline{14}} .1(0.06)$ & 二 & $\overline{\overline{7}}$ & 二 \\
\hline Trace & $17.7 \pm 2.2$ & $39.0 \pm 1.6$ & Trace & Trace & $2.6 \pm 0.5$ & Trace & $2.9 \pm 0.7$ & $11.2 \pm 1.3$ & $6.6 \pm 1.2$ & $3.3 \pm 1.0$ & $2.5 \pm 0.5$ & Trace \\
\hline$\overline{\overline{6.2}}(0.01)$ & - & $\overline{\bar{\sigma}}_{6.5(0.01)}$ & $\bar{Z}_{2.7}(0.00)$ & $\overline{\overline{3.1}}(0.00)$ & 二 & E & 二 & $\overline{\overline{9}}_{9.8(0.01)}$ & $\overline{\bar{Z}}$ & 二 & 二 & 二 \\
\hline Trace & $17.2 \pm 3.0$ & $42.1 \pm 3.5$ & Trace & Trace & $2.6 \pm 0.5$ & Trace & $2.9 \pm 0.3$ & $12.8 \pm 3.4$ & $8.2 \pm 2.1$ & $3.0 \pm 1.8$ & $1.9 \pm 0.5$ & Trace \\
\hline 三 & 二 & $\overline{-}$ & E & $=$ & E & 二 & $=$ & 二 & 二 & $\overline{-}$ & $=$ & $=$ \\
\hline Trace & $20.1 \pm 4.0$ & $34.4 \pm 4.6$ & Trace & Trace & $3.0 \pm 0.8$ & Trace & $2.5 \pm 0.6$ & $13.6 \pm 4.5$ & $8.8 \pm 3.0$ & $2.5 \pm 1.1$ & $4.1 \pm 0.6$ & Trace \\
\hline $\begin{array}{l}2.3 \\
2.5 \\
3.4\end{array}$ & $\begin{array}{l}2.4 \\
2.4 \\
2.2\end{array}$ & $\begin{array}{l}9.2 \\
7.2 \\
7.4\end{array}$ & $\begin{array}{l}21.8 \\
24.7 \\
18.3\end{array}$ & $\begin{array}{l}\text { Trace } \\
0.9 \\
0.8\end{array}$ & $\begin{array}{l}1.2 \\
0.4 \\
0.1\end{array}$ & $\begin{array}{l}4.2 \\
4.4 \\
4.3\end{array}$ & $\begin{array}{l}0.4 \\
0.3 \\
0.6\end{array}$ & $\begin{array}{l}5.6 \\
5.1 \\
8.6\end{array}$ & $\begin{array}{l}4.0 \\
4.7 \\
8.6\end{array}$ & $\begin{array}{l}0.3 \\
0.2 \\
2.2\end{array}$ & $\begin{array}{l}4.6 \\
5.2 \\
7.8\end{array}$ & $\begin{array}{l}2.7 \\
1.9 \\
4.2\end{array}$ \\
\hline $1.5 \pm 0.4$ & $3.9 \pm 0.7$ & $7.7 \pm 1.0$ & $27.5 \pm 2.2$ & $0.6 \pm 0.2$ & $2.0 \pm 0.7$ & $2.0 \pm 0.7$ & $1.4 \pm 0.6$ & $4.2 \pm 1.1$ & $5.8 \pm 1.3$ & $2.1 \pm 0.5$ & $4.8 \pm 0.1$ & $4.3 \pm 1.1$ \\
\hline $\begin{array}{l}2.4 \\
2.6 \\
3.5\end{array}$ & $\begin{array}{l}2.7 \\
2.4 \\
2.2\end{array}$ & $\begin{array}{r}10.0 \\
7.4 \\
7.6\end{array}$ & $\begin{array}{l}21.8 \\
24.7 \\
18.4\end{array}$ & $\begin{array}{l}\text { Trace } \\
0.9 \\
0.9\end{array}$ & $\begin{array}{l}1.2 \\
0.4 \\
0.1\end{array}$ & $\begin{array}{l}4.2 \\
4.4 \\
4.3\end{array}$ & $\begin{array}{l}0.5 \\
0.3 \\
0.7\end{array}$ & $\begin{array}{l}5.9 \\
5.3 \\
8.9\end{array}$ & $\begin{array}{l}4.2 \\
4.9 \\
9.0\end{array}$ & $\begin{array}{l}0.3 \\
0.2 \\
2.2\end{array}$ & $\begin{array}{l}4.6 \\
5.2 \\
7.9\end{array}$ & $\begin{array}{l}2.7 \\
1.9 \\
4.2\end{array}$ \\
\hline $1.5 \pm 0.4$ & $5.4 \pm 1.0$ & $11.3 \pm 1.4$ & $27.6 \pm 2.2$ & $0.6 \pm 0.2$ & $2.3 \pm 0.7$ & $2.0 \pm 0.7$ & $1.7 \pm 0.7$ & $5.4 \pm 1.3$ & $6.6 \pm 1.5$ & $2.4 \pm 0.5$ & $5.1 \pm 0.1$ & $4.4 \pm 1.2$ \\
\hline
\end{tabular}

of normal subjects and severely burned patients. droxyphenylacetic acid; MH P Conj, 3-methoxy-4-hydroxyphenylglycol conjugate; MHP 


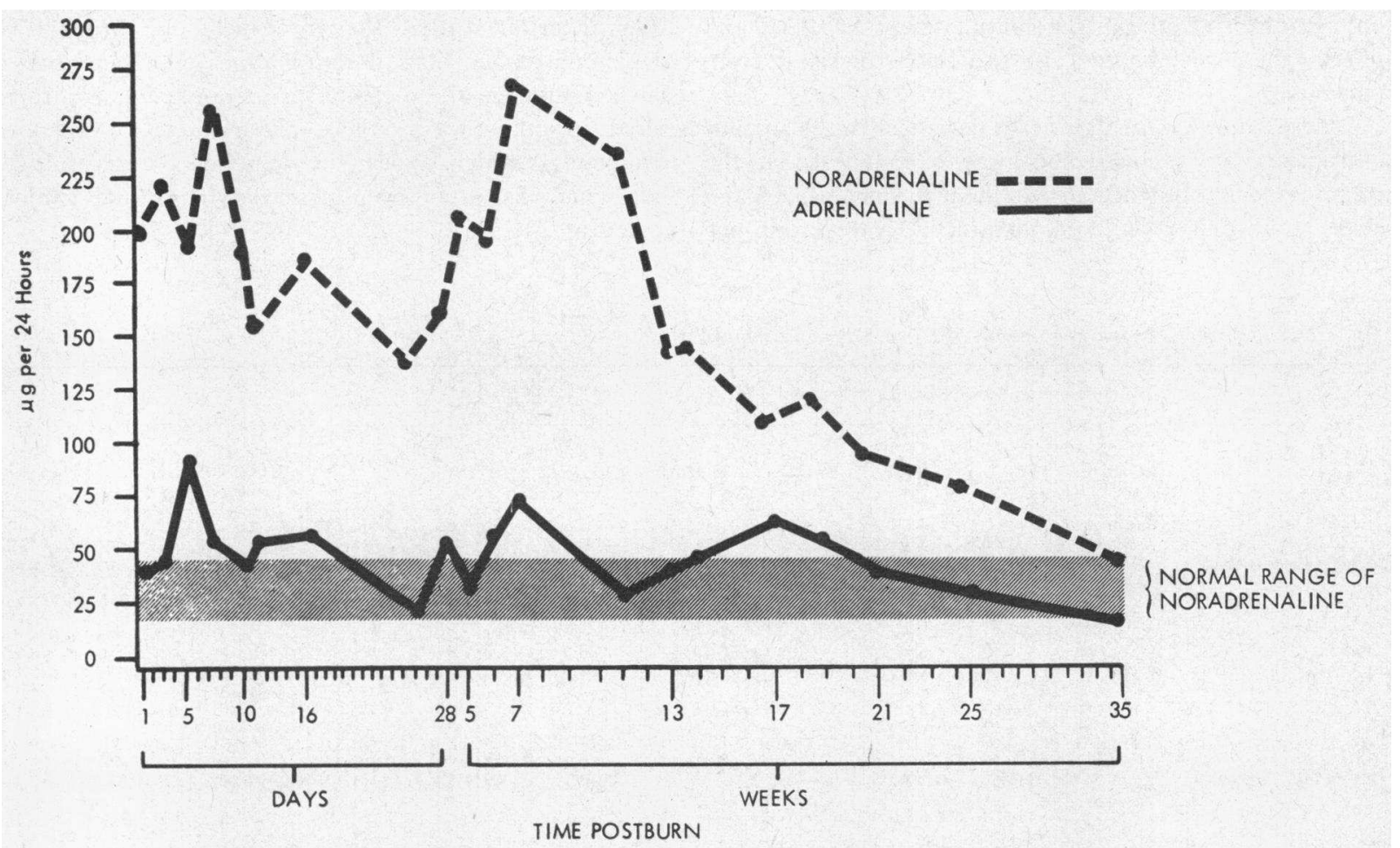

FIGURE 3 The urinary adrenaline and noradrenaline output of one burned patient who recovered; adrenaline and noradrenaline are calculated in $\mu \mathrm{g} / 24 \mathrm{hr}$. The normal range of noradrenaline is $20-45 \mu \mathrm{g} / 24 \mathrm{hr}$; the normal range of adrenaline is $5-25 \mu \mathrm{g} / 24 \mathrm{hr}$.

The amount of radioactivity recovered as adrenaline was small and not in sufficient quantity to monitor.

\section{DISCUSSION}

It is generally accepted that almost any severe stressful condition will activate the sympathicoadrenal medullary system into releasing increased amounts of noradrenaline and adrenaline. Severe thermal injury represents one of the most potent stresses. Immediately after thermal injury, there is a marked increase in the urinary output of both adrenaline and noradrenaline, and this elevated output continues for most of the recovery period (6) (see Fig. 3). If the stress of severe burns continues for a protracted period of time, the adrenal medulla and the sympathetic nerves can be partially or totally depleted of their respective hormones $(10,11)$. It was previously shown that of the severely burned patients that died, approximately one-third showed at the time of death a subnormal output of noradrenaline and subnormal noradrenaline content of the sympathetic ganglia and axon, a condition commensurate with sympathetic nerve depletion (11). Furthermore, over two-thirds of the cases that died showed at the time of death a subnormal output of adrenaline and an adrenal gland that was partially or totally depleted of its adrenaline and noradrenaline content (10). Whereas this depletion was not the cause of death in these patients, it nevertheless was a contributing factor and therefore imposes the question of how this depletion should be treated. The approach considered in these experiments was to infuse the severely burned subjects with a noradrenaline-adrenaline precursor, i.e., dopamine (3,4-dihydroxyphenylethylamine, hydroxytyramine) (see Fig. 1).

By evaluating the rate at which dopamine- $2-{ }^{14} \mathrm{C}$ is synthesized into noradrenaline and noradrenaline metabolic products, this would give some indication as to its utilization and turnover and thereby its possible effectiveness in treating a noradrenaline-adrenaline depletion. From the results it is evident that there is an increase in the rate of utilization of dopamine, i.e. normally $87.6 \pm 3.1 \%$ of the total radioactivity is recovered within $24 \mathrm{hr}$ after an infusion of dopamine- $2-{ }^{14} \mathrm{C}$, but in the severely burned patients $93.1,97.3$, and $97.5 \%$ were recovered in $24 \mathrm{hr}$ (see Table I). To state this differently, in the burned subject very little radioactivity is recovered after $24 \mathrm{hr}$, i.e. less than $2.5 \%$ in the two patients that died, whereas, in normal subjects $12.4 \%$ is recovered after $24 \mathrm{hr}$ (see Table I, under per cent of the infused dose recovered), thereby indicating that the dopamine 
is being utilized at a far greater rate than it is in normal subjects.

The fact that in the burned subjects there was marked decrease in the amount of radioactivity recovered as noradrenaline in all collection periods and no radioactive noradrenaline recovered after $24 \mathrm{hr}$, but a concomitant increase in the metabolic products of noradrenaline indicates that the infused dopamine- $2-{ }^{14} \mathrm{C}$ was rapidly synthesized to endogenous noradrenaline and then rapidly released and metabolized (see Table I, comparison with normal subjects). The metabolic products of noradrenaline that demonstrated this increase in metabolism were: MOMA (the principal metabolic product of noradrenaline) in the early collection periods, noradrenaline conjugate, and NM conjugate.

In normal subjects approximately $25 \%$ of the dopamine is converted to noradrenaline and metabolic products of noradrenaline and approximately $75 \%$ to metabolic products of dopamine, i.e., principally DOPAC, homovanillic acid, etc., and their respective conjugates (see Table I) (12). However, in the severely burned subjects about $30 \%$ of the dopamine was converted to noradrenaline and its metabolic products and $70 \%$ to metabolic products of dopamine. This increase in conversion to noradrenaline and noradrenaline metabolic products, at the expense of the dopamine metabolic products, indicates that in the burned patients there is a compensatory shift towards noradrenaline synthesis and utilization.

These results give indirect evidence for the need for dopamine in severely burned subjects with possible sympathicoadrenal medullary depletion. However, they do not indicate whether or not a more distant precursor to noradrenaline and adrenaline, i.e. DOPA (3, 4-dihydroxyphenylalanine), or even tyrosine, would be useful (see Fig. 2). Presumably, the most immediate precursor would be the most useful; nevertheless, DOPA, which is readily decarboxylated to dopamine, could be of equal or even greater value. The experiments herein described are not intended to indicate the clinical value of dopamine in burned subjects, but rather to demonstrate biochemically its rationale and usefulness; the clinical evaluation of using dopamine in severely burned patients will be subsequently reported.

\section{ACKNOWLEDGMENTS}

We are indebted to Dr. B. W. Haynes, Jr., of the Medical College of Virginia, and to Dr. Robert E. Knowling of Knoxville, Tenn., for permitting us to study their patients.

This study was supported by U. S. Public Health Service Grant AM 12805.

\section{REFERENCES}

1. Franksson, C., C. A. Gemzell, and U. S. von Euler. 1954. Cortical and medullary adrenal activity in surgical and allied conditions. J. Clin. Endocrinol. 14: 608.

2. von Euler, U. S. 1956. Noradrenaline: Chemistry, Physiology, Pharmacology, and Clinical Aspects. Charles C Thomas, Springfield, Ill.

3. Goodall, McC. 1962. Sympatho-adrenal response to gravitational stress. J. Clin. Invest. 41: 197.

4. Bloom, G., U. S. von Euler, and M. Frankenhaeuser. 1963. Catecholamine excretion and personality traits in paratroop trainees. Acta Physiol. Scand. 58: 77.

5. Goodall, McC. 1967. Effect of neutron and gamma radiation on adrenaline and noradrenaline release in the human. Health Phys. 14: 199.

6. Goodall, McC., C. Stone, and B. W. Haynes, Jr. 1957. Urinary output of adrenaline and noradrenaline in severe thermal burns. Ann. Surg. 145: 479.

7. Birke, G., H. Dunér, S. O. Liljedahl, B. Pernow, L. O. Plantin, and L. Troell. 1957. Histamine, catecholamines and adrenocortical steroids in burns. Acta Chir. Scand. 114: 85 .

8. Harvengt, C. 1968. Le Système Adrénergique et le Choc Circulatoire Précoce des Brûlés. Editions Arscia, S. A., Brussels.

9. Dolecek, R., L. Endryas, J. Kalina, L. Klaubusay, and A. Tichy. 1969. The Metabolic Response of the Burned Organism. Charles C Thomas, Springfield, Ill.

10. Goodall, McC., and B. W. Haynes, Jr. 1960. Adrenal medullary insufficiency in severe thermal burn. J. Clin. Invest. 39: 1927.

11. Goodall, McC., and J. A. Moncrief. 1965. Sympathetic nerve depletion in severe thermal injury. Ann. Surg. 162: 893.

12. Goodall, McC., and H. Alton. 1968. Metabolism of 3-hydroxytyramine (dopamine) in human subjects. Biochem. Pharmacol. 17: 905.

13. Goodall, McC., W. R. Harlan, Jr., and H. Alton. 1968. Decreased noradrenaline (norepinephrine) synthesis in neurogenic orthostatic hypotension. Circulation. 38: 592. 